DOI: https://doi.org/10.24297/jap.v16i1.8328

\title{
Enhancement Of MRI Imaging by Combining Ramp Sampling and Parallel Imaging Techniques in Cerebral Tumors
}

\author{
Ehab A. Hegazy \\ Department of pharmaceutical chemistry, Faculty of pharmacy, Delta University of science and technology \\ Ehab.hegazy@deltauniv.edu.eg, Ehabhegazy99@yahoo.com
}

\begin{abstract}
Our aim was to decrease geometric distortion artifact in DWI on brain by using different MR techniques such as ramp sampling and parallel imaging. The study was done on 15 patients, They were subject to routine brain MRI examination for different symptoms, examination was done on $1.5 \mathrm{~T}$ scanner, patients were divided to three group five patient in each group, geometric distortion in frontal and occipital lobe measured in the routine acquired DWI and after used the interested strategy compared to anatomical T2-FSE acquired in the routine examination then reduction percentage for each strategy was calculated. Application of parallel technique imaging showed significant artifact reduction in frontal lobe with approximately $54.36 \%$ and about $34.8 \%$ in occipital lobe, while ramp sampling showed reduction with approximately $19 \%$ in frontal lobe and reduced artifact by $41.58 \%$ in the occipital lobe.
\end{abstract}

Finally we conclude that using new techniques such as ramp sampling and parallel imaging used with EPI data acquisition reduced geometric distortion artifact and increased geometric resolution.

Keywords: Echo planner, Brain tumors, Imaging quality, Ramp sampling

\section{Introduction}

Magnetic field gradient was used in diffusion MRI to generate brain image and considered as the clinical domain routine when (Echo Planar Imaging) was available on MRI devices [1]. Mapping of water molecules Diffusion MRI non-invasively (magnetic resonance imaging) helps in imaging of brain microstructural characteristics in-vivo [2]. Two sharp intense magnetic fields were used to generate MR signals which are very sensitive to water movements [2]. Diffusion-weighted magnetic resonance imaging uses echo-planner technique as gold standard procedure imaging in MRI of brain [3]. The main disadvantage of EPI is artifact caused by main magnetic field inhomogeneity as investigated by many clinical [4], [5], [6].This artifacts is major problem in air rich tissues or air edges which separates bones and muscles this artifact is known as susceptibility distortion [7], [8]. Misalignment of data can produce change in organs anatomy by several millimeters, which can reduce the accuracy of image analysis in the brain lesions [6], [9], [10]. It was recognized that maximum error happen in phase encoding direction which generated by phase-encoding steps [11].

DWI is the optimum technique in tissues with high gradient strength like nerves and brain due to its signal to noise ratio[12] [13].Signal distortion and bad sharpness in EPI is produced as results of absence of time at the peak of gradient wave front [14].

The aim of this study was to reduce geometric distortion artifact and enhance resolution for EPI-DW images for the brain. We have used two different MRI strategies which are ramp sampling and parallel imaging. Ramp Sampling allowing echo sampling during ramp ups and downs of the frequency encoding gradient therefore ramp sampling reduce echo spacing, allow faster sampling and improve image resolution [14]. 


\section{1- $\quad$ Materials and method}

\subsection{Patients}

Fifteen patients were selected form fifty patient with normal brain anatomy, in Mansoura advanced radiology center, Mansoura Egypt.

\subsection{MR examination}

Device of magnetic field strength a 1.5 tesla is used type (GEHC) and sigma scanner with high resolution is used. DWI techniques are used added to ramp sampling asset or both. Dicom viewer soft is used to investigate imaged before and after using new strategy and for measurement of geometric distortion.

\section{2- $\quad$ Results and discussion}

For calculating the reduction percentage of each strategy, we divided the patients in to three groups, each group include five cases with different ages and sex, for first group we added DWI sequence with ramp sampling and compared the acquired images with that one acquired with conventional parameters, for the second group we added DWI sequence with ASSET and compared the acquired images with that one acquired with conventional parameters, for the last group we acquired DWI in the routine examination with ramp sampling technique then we added DWI sequence with both ramp sampling and ASSET then compared the acquired images with that one acquired with ramp sampling only. Then average percentage was calculated.

\subsection{Effect of Ramp sampling}

In the following first five cases $[1,2,3,4$ and 5] we added the ramp sampling to the DWI in a separate sequence in addition to the routine MR examination and compered the acquired images with that one acquired without the ramp sampling as following:

\subsubsection{Case $[1]$}

In this case we choose two different slices figure (1) \& (2) to measure the geometric artifact in frontal lobe figure (1) a slice that suffer from voxel displacement only on the anterior region, and the geometric artifact in posterior lobe in another slice in the upper brain as figure (2) shows voxel displacement in both anterior and posterior region. For each slice we have used the similar slice of T2 for measuring the degree of displacement in both anterior and posterior region. According to figure (2), ramp sapling has little impact on decreasing voxel displacement in anterior region unlike decreasing artifact in posterior region and decreasing artifact in anterior region in slice near frontal sinus figure 2 . 


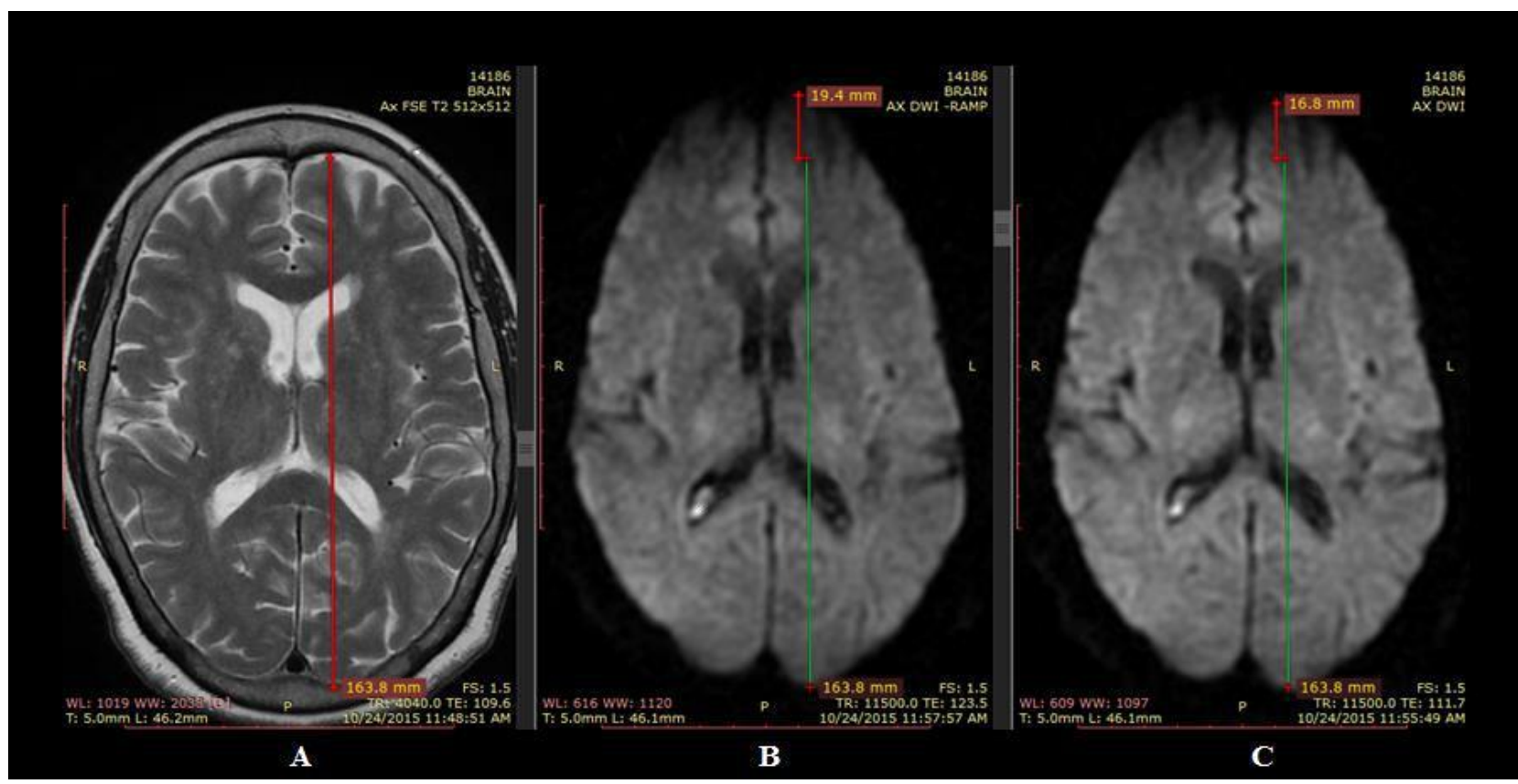

Figure (1): Slice one with voxel displacement.

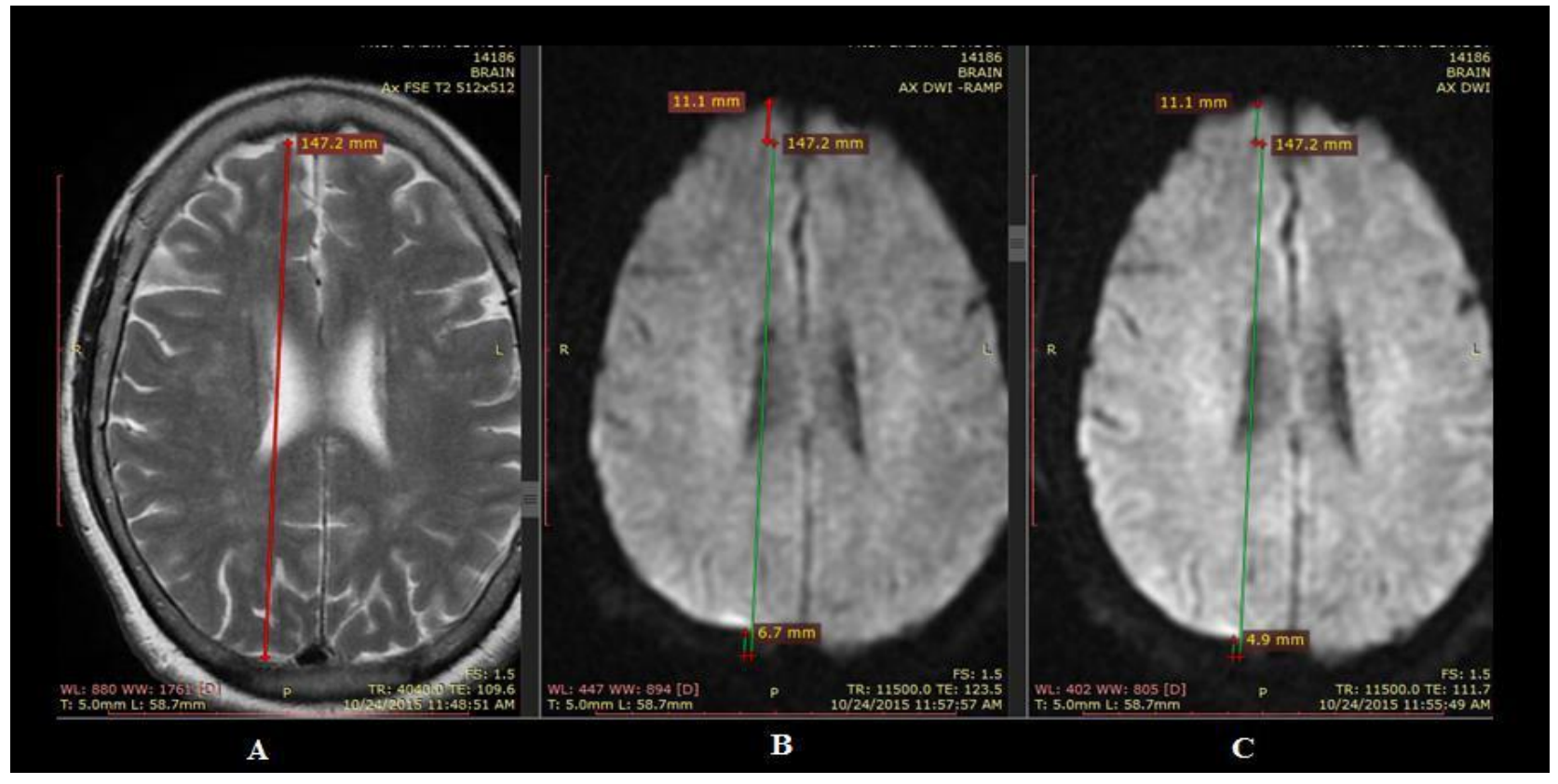

Figure (2): Slice two at different depth

\subsubsection{Case [2]}

As done in case $[\mathrm{A}]$ two different slices for second case were chosen for studying the effect of ramp sampling as Figure (3) \& (4) show structure of normal brain with geometric distortion artifact in anterior region in DW image with conventional parameters (B) and the reduction after ramp sampling (C). 


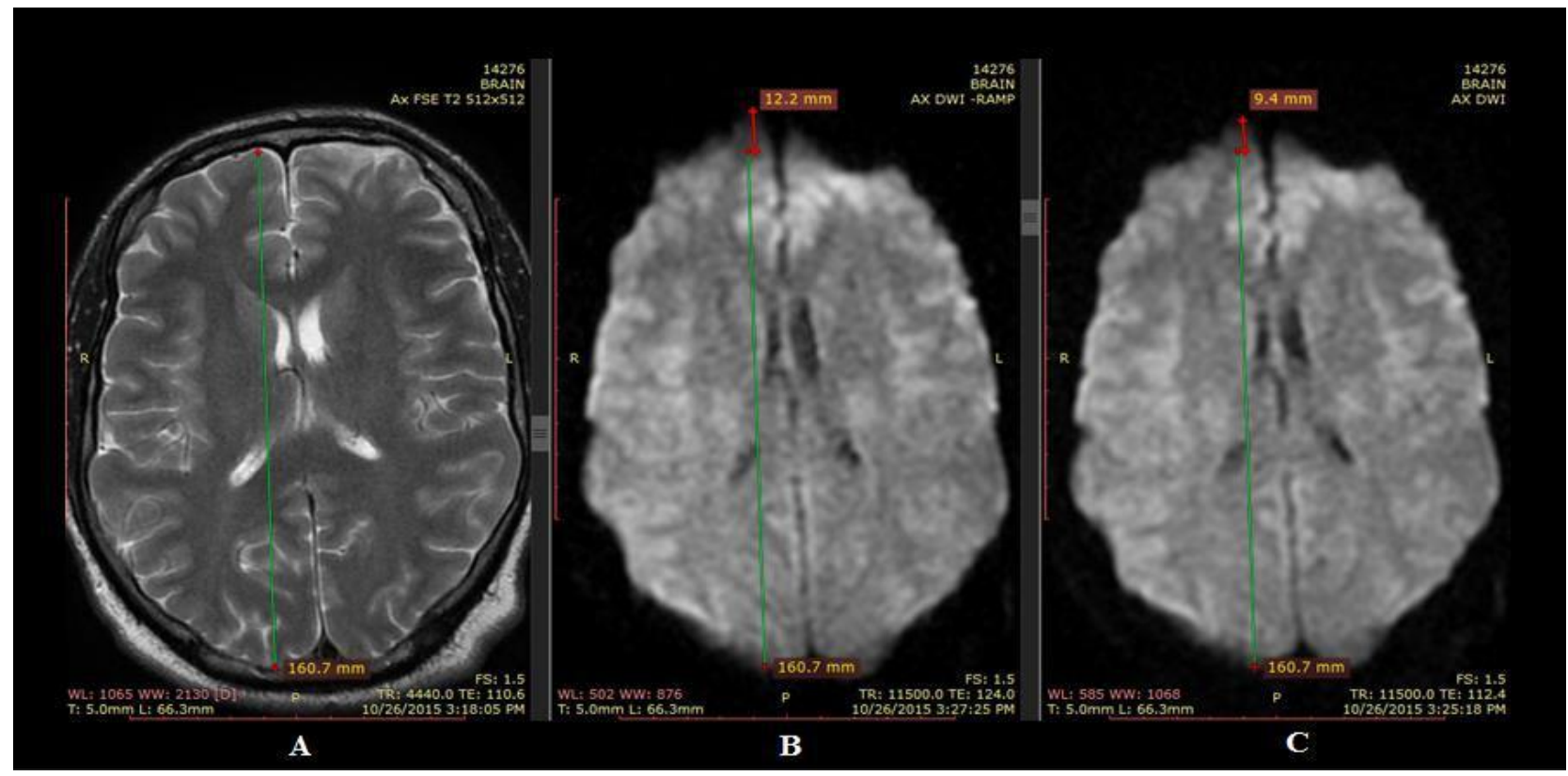

Figure (3): patient 2 first slice with geometric distortion

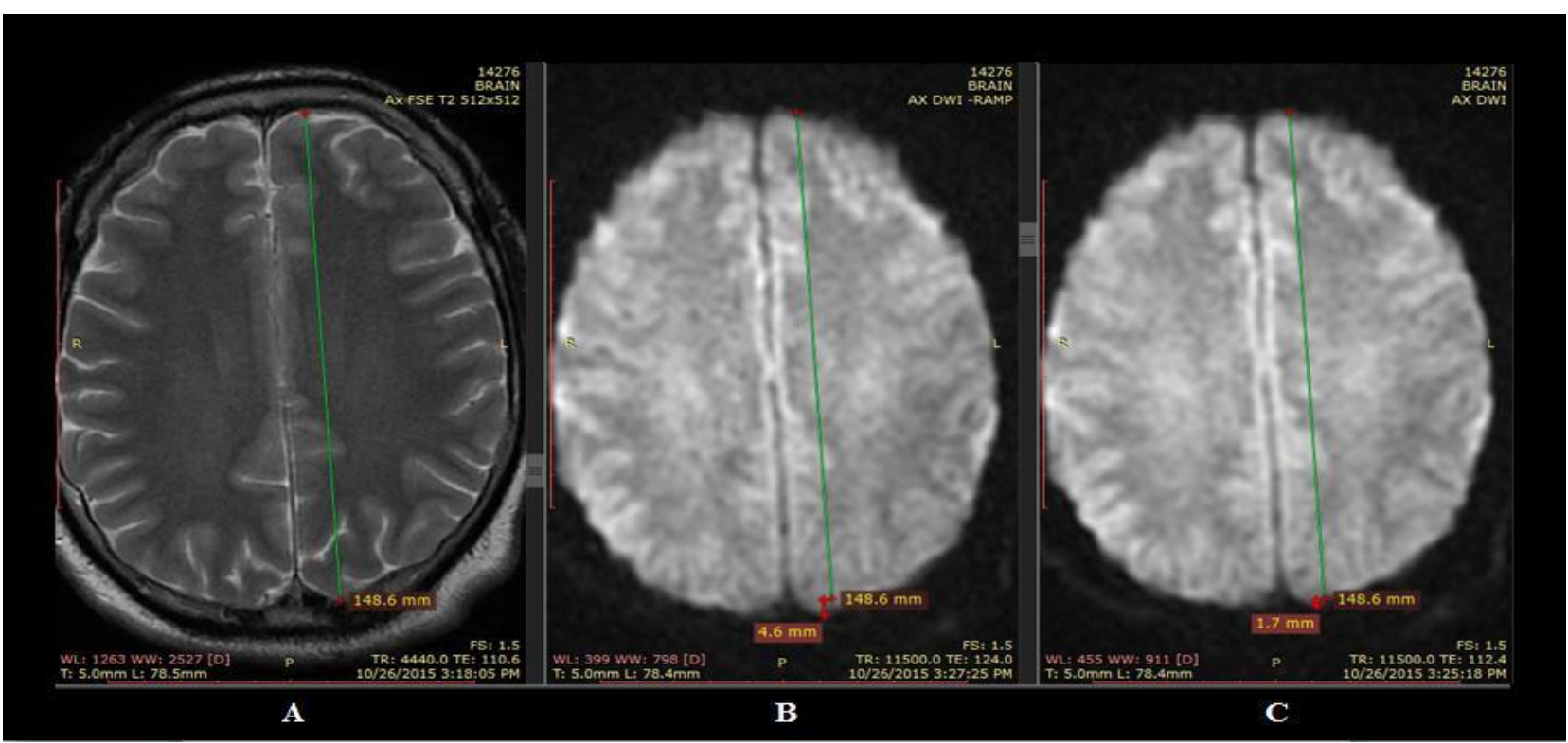

Figure (4): Patient 2 second slice with geometric distortion

\subsubsection{Case [3]}

Two different slices for third case were chosen for studying the effect of ramp sampling as Figure (5) shows distortion artifact in anterior region without (B) and after (C) ramp sampling, figure (6) shows another slice in upper brain with geometric distortion artifact in anterior and posterior region and the reduction in posterior region in DW-EPI image with conventional parameters (B) and the reduction after ramp sampling (C). 


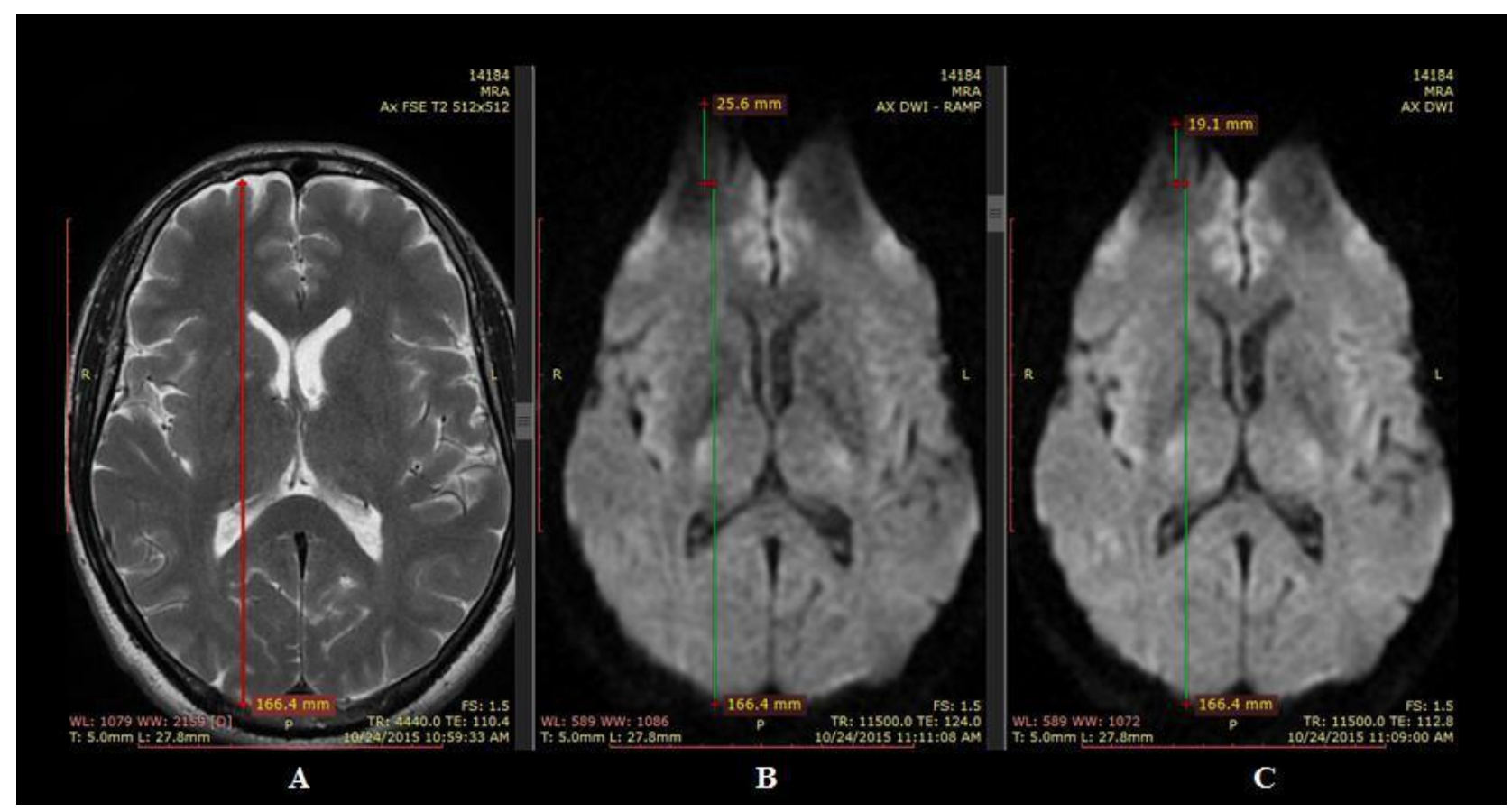

Figure (5): patient 3 first slice distortion artifact in anterior region.

As seen in figure (5) DWI acquired without ramp sampling (B) suffer from blurring and low resolution unlike image $(C)$ that acquired with ramp sampling which shows increase in resolution, better contrast between different tissue and incensement in signal strength.

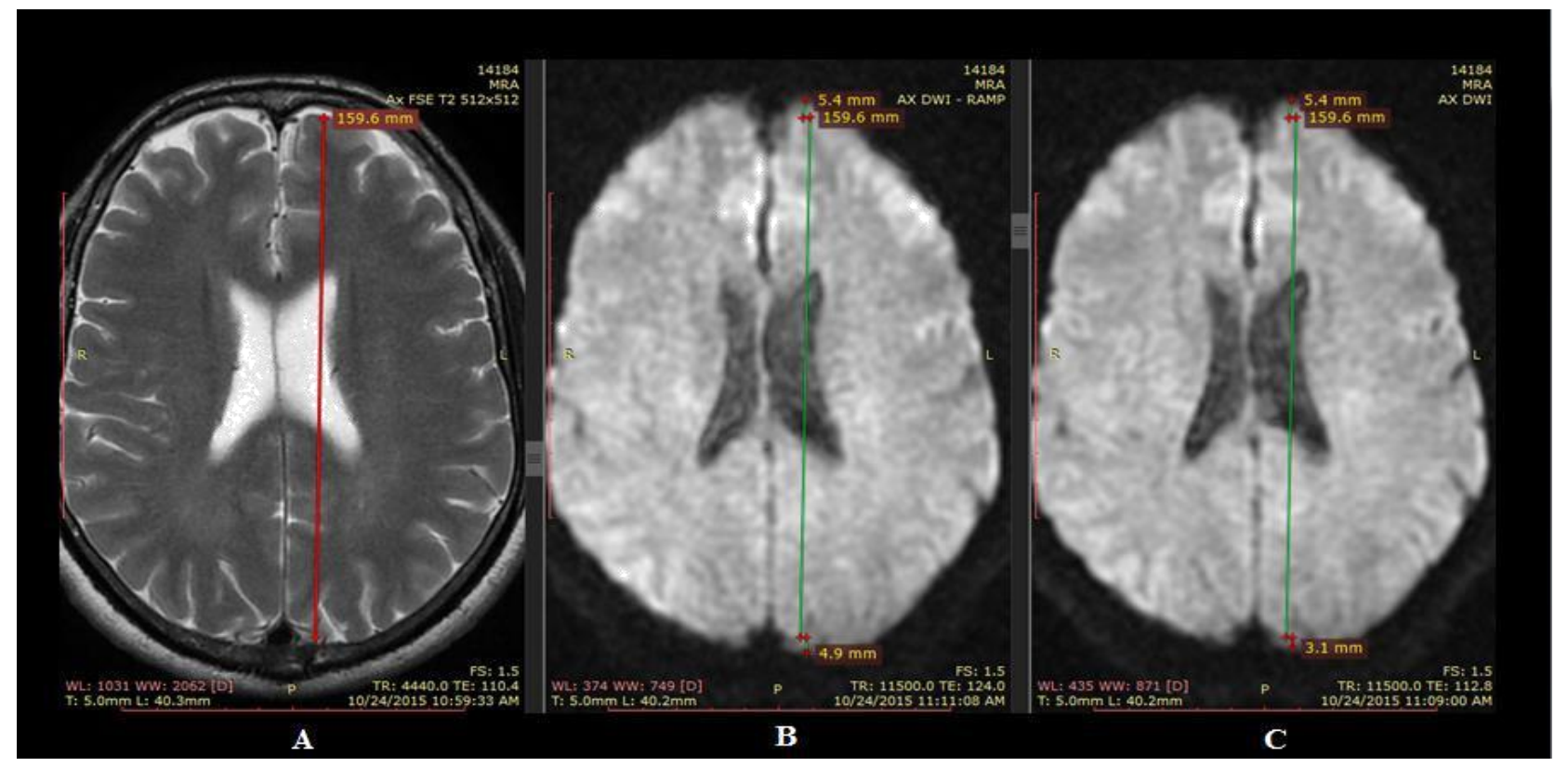

Figure (6): patient 3 second slice distortion artifact in anterior region.

\subsubsection{Case [4]}

Figure (7) shows normal structure of brain for fourth case. The selected slice shows the voxel displacement in anterior and posterior region, $(C)$ shows the reduction in both regions after using ramp sampling. 


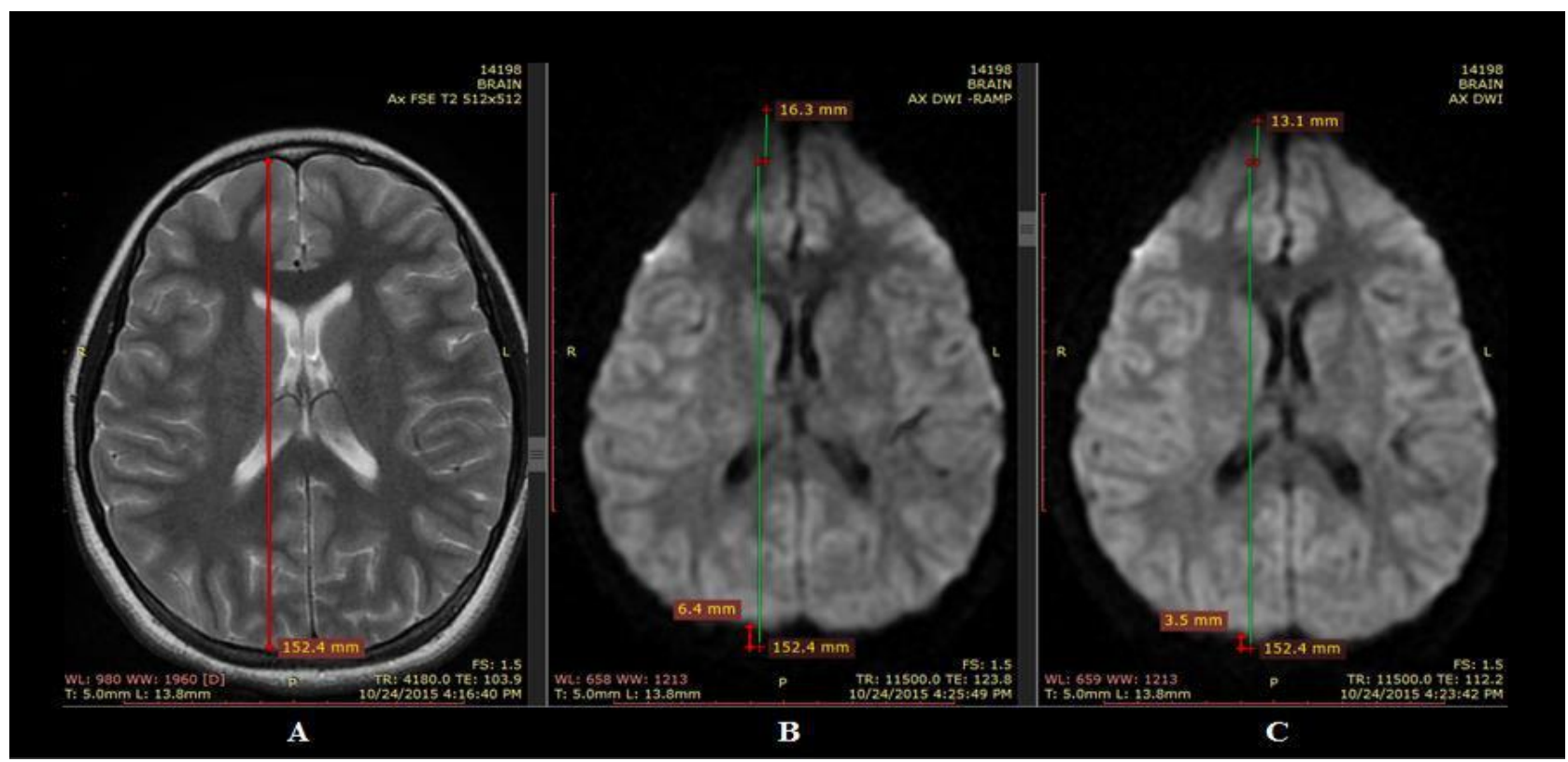

Figure (7): Patient 4 voxel displacement in anterior and posterior region.

\subsubsection{Case [5]}

Figure (8) shows the last case in this group for studying the effect of ramp sampling on SE/EPI DWI, measurements shows decreasing in geometric distortion artifact in anterior and posterior lobe of normal brain.

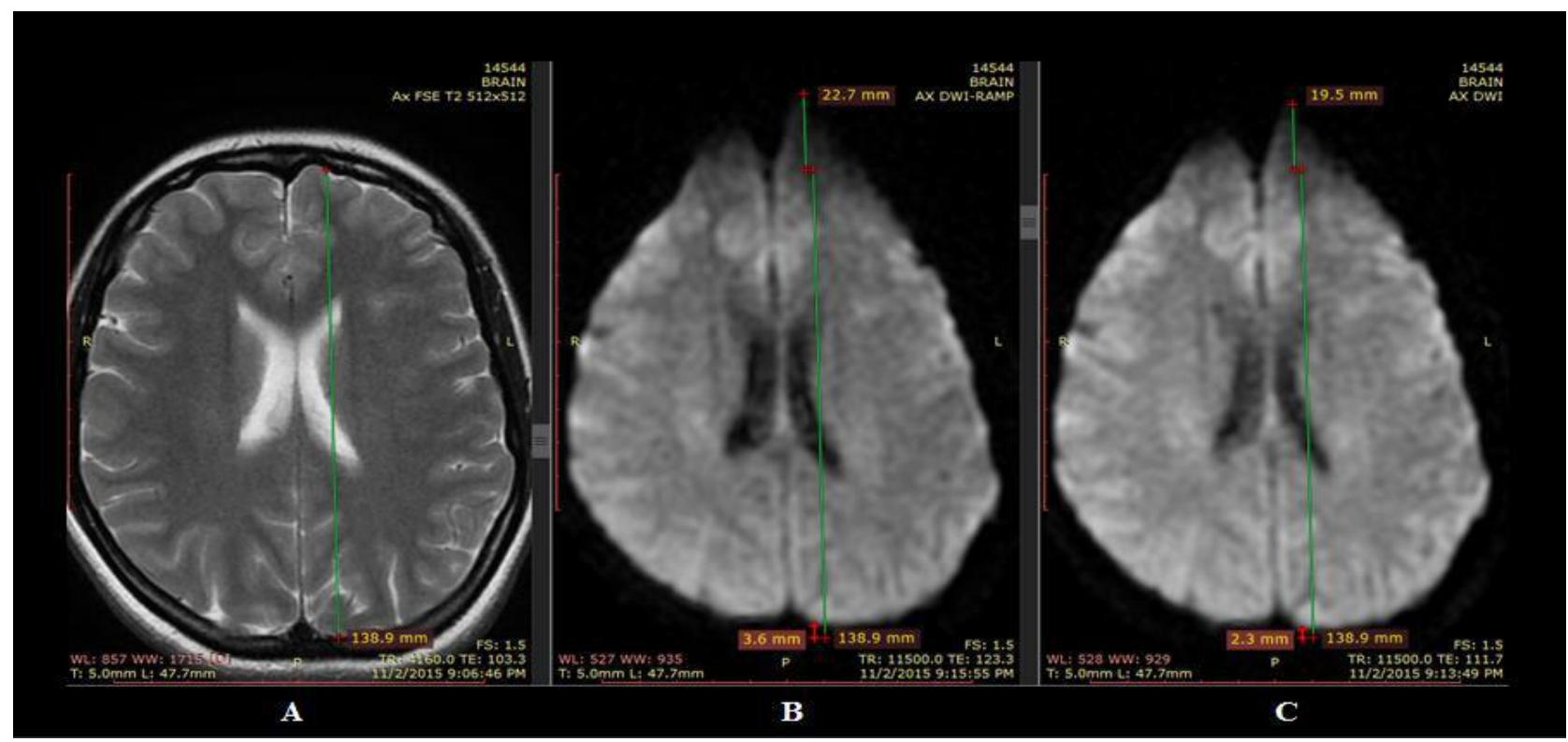

Figure (8): patient 4 case with SE/EPI DWI

Table (1) shows reduction percentage for voxel displacement in anterior region in DWI before and after using ramp sampling for the examined five cases. Table (2) shows the reduction percentage in posterior region. 
Table [1] voxel displacement $(\mathrm{mm})$ in anterior region after using ramp sampling compared with those one without ramp sample.

\begin{tabular}{|c|c|c|c|}
\hline Cases & $\begin{array}{c}\text { voxel displacement }(\mathbf{m m}) \text { in } \\
\text { DWI without ramp sampling }\end{array}$ & $\begin{array}{c}\text { voxel displacement }(\mathbf{m m}) \text { in } \\
\text { DWI with ramp sampling }\end{array}$ & Reduction percentage \\
\hline 1 & 19.4 & 16.8 & $13.40 \%$ \\
\hline 2 & 12.2 & 9.4 & $23.00 \%$ \\
\hline 3 & 25.6 & 19.1 & $25.40 \%$ \\
\hline 4 & 16.3 & 13.1 & $19.60 \%$ \\
\hline 5 & 22.7 & 19.5 & $14.00 \%$ \\
\hline
\end{tabular}

Table [2] voxel displacement $(\mathrm{mm})$ in posterior region after using ramp sampling compared with those one without ramp sample.

\begin{tabular}{|c|c|c|c|}
\hline Cases & $\begin{array}{c}\text { voxel displacement }(\mathbf{m m}) \text { in } \\
\text { DWI without ramp sampling }\end{array}$ & $\begin{array}{c}\text { voxel displacement }(\mathbf{m m}) \text { in } \\
\text { DWI with ramp sampling }\end{array}$ & Reduction percentage \\
\hline 1 & 6.7 & 4.9 & $26.90 \%$ \\
\hline 2 & 4.6 & 1.7 & $36.00 \%$ \\
\hline 3 & 9.4 & 6.3 & $36.70 \%$ \\
\hline 4 & 6.4 & 3.5 & $36.30 \%$ \\
\hline 5 & 3.6 & 2.3 & \\
\hline
\end{tabular}

According to table [1] Ramp sampling enhance resolution of frontal lobe of brain with approximately $19 \%$ and about $41.58 \%$ reduction in the occipital lobe according to table [2].

\subsection{Effect of Parallel imaging}

In the second group the five cases $[6,7,8,9$ and 10] were subjected to routine MR examination for brain and a separate DWI sequence acquired with ASSET technique then the resultant images were compared with that one acquired with neither ramp sampling nor ASSET.

\subsubsection{Case [6]}

In this case one slice have voxel displacement in both anterior and posterior region was choose for 
measurement of this displacement compared to T2 of the same slice as figure (9) shows.

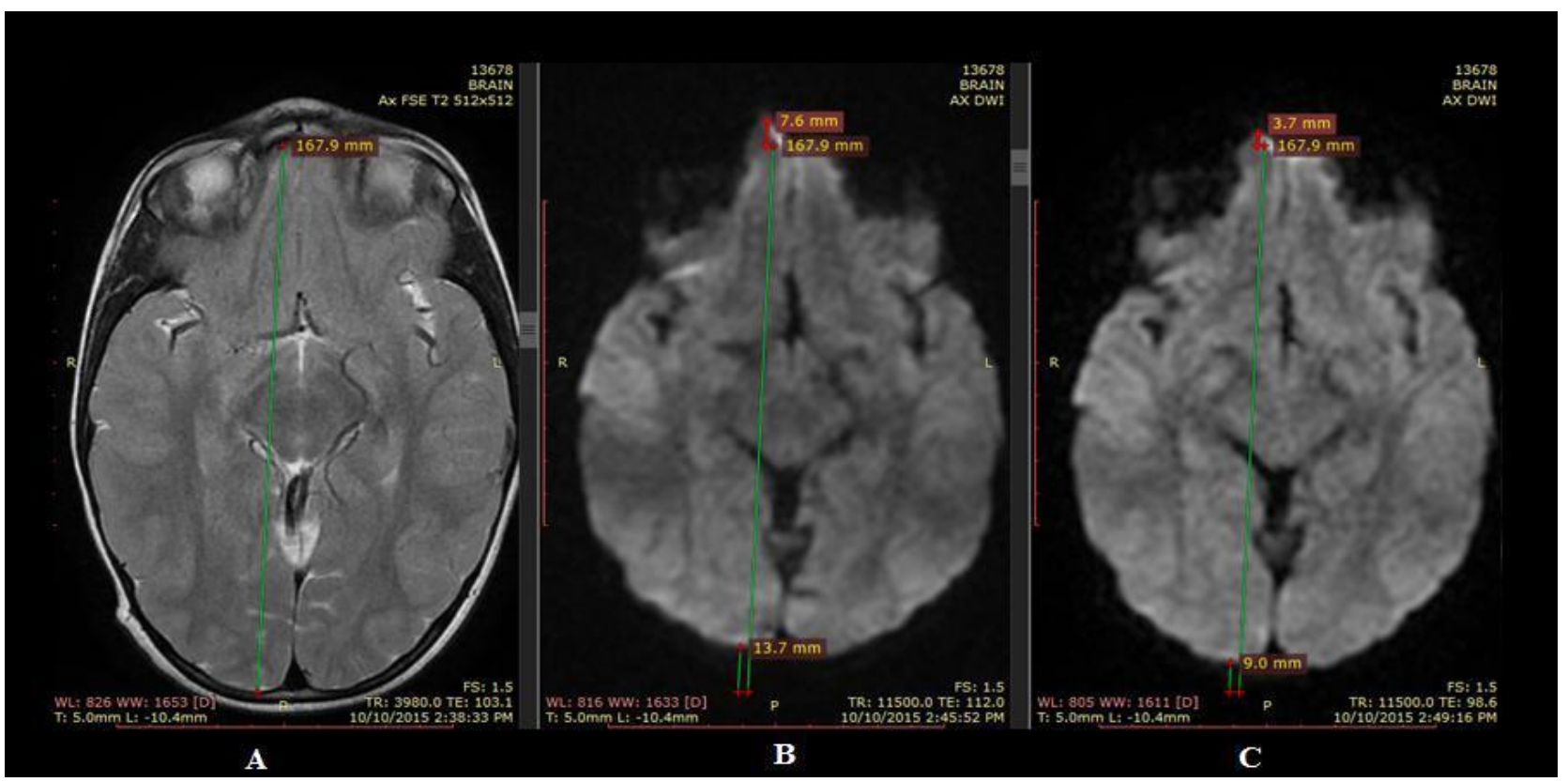

Figure (9): Patient 6 voxel displacement in both anterior and posterior.

\subsubsection{Case [7]}

Figure (10) shows the result for second case after using ASSET (C).

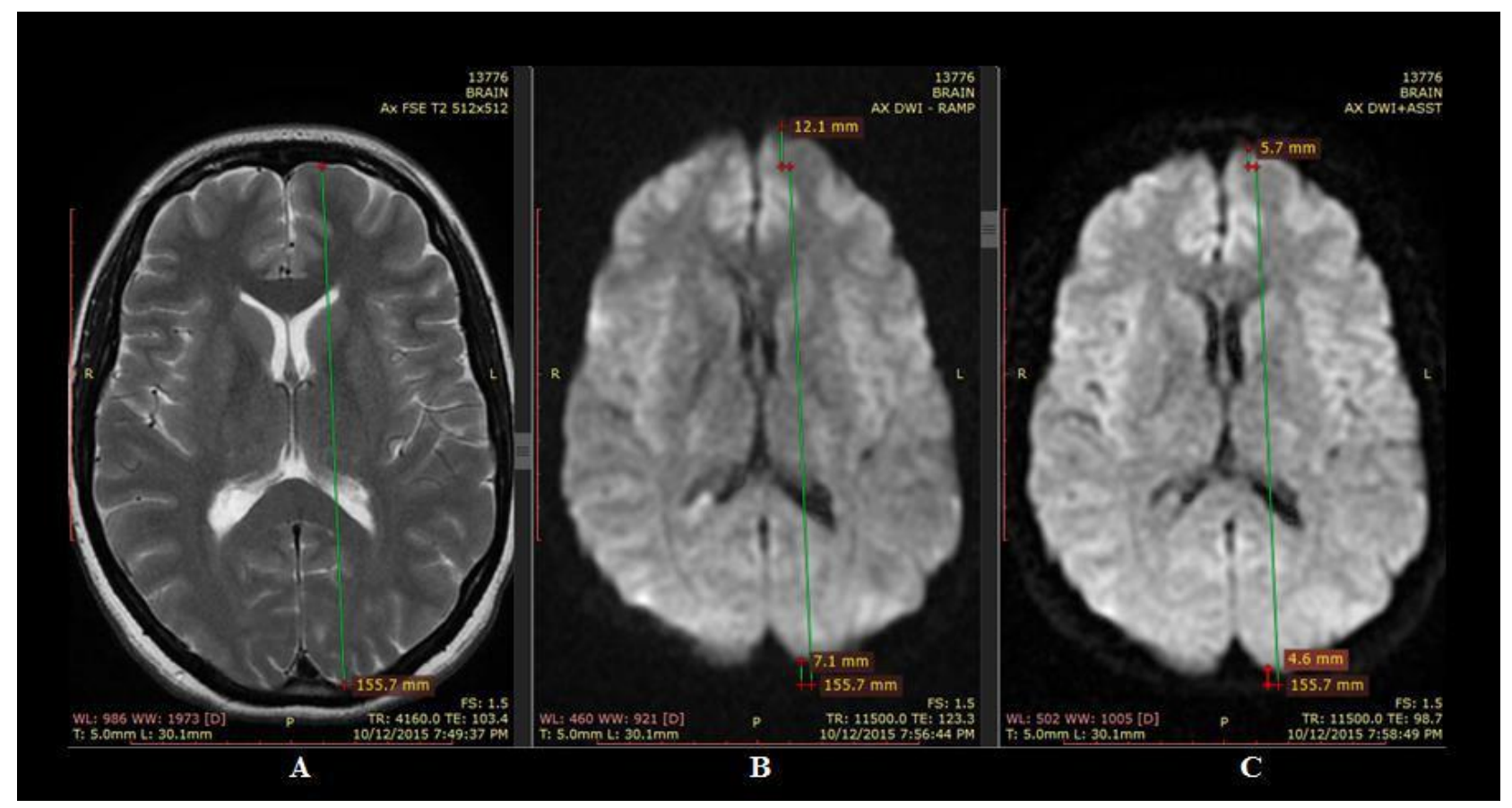

Figure (10): Patient 7 voxel displacement in both anterior and posterior using asset.

it is obvious that in addition to decreasing voxel displacement in anterior and posterior region using ASSET increase resolution and decrease noise when compared with the same slice acquired without ASSET (B), T2-FSE used as reference (A). 


\subsubsection{Case [8]}

Figure (11) shows structure of normal brain for a pediatric patient as a stretching in DWI acquired without ASSET (B) compared with the noticeable decline in this after using ASSET (C)

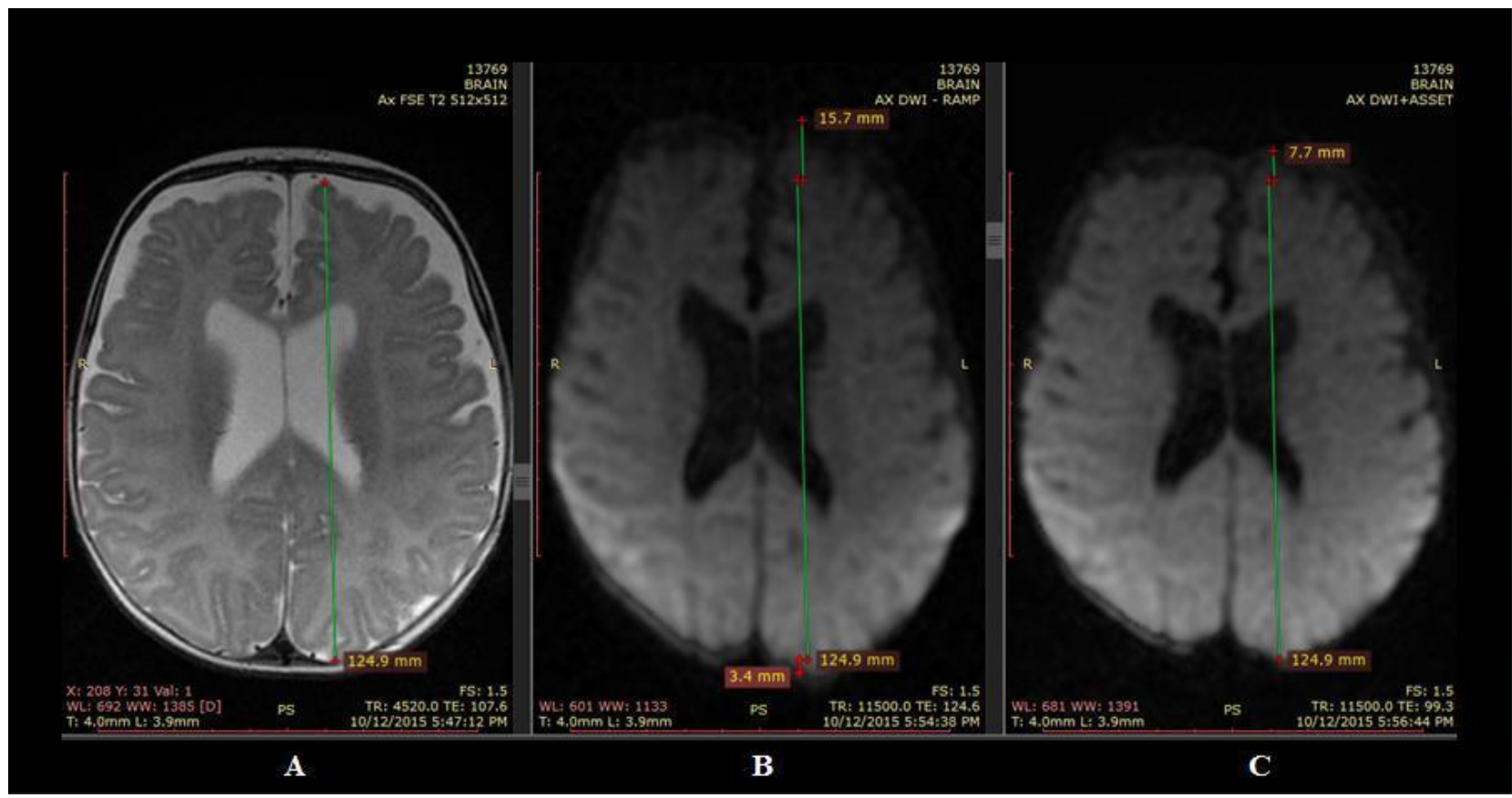

Figure (11): Patient 8 pediatric case.

\subsubsection{Case [9]}

Another case clearly shows the image defects in DWI and the positive effect of using ASSET with EPI-DWI. Figure (12) shows slice of normal brain for the fourth case in this group, ASSET improve image quality and decrease geometric distortion artifact $(C)$ when compared with those one acquired without ASSET

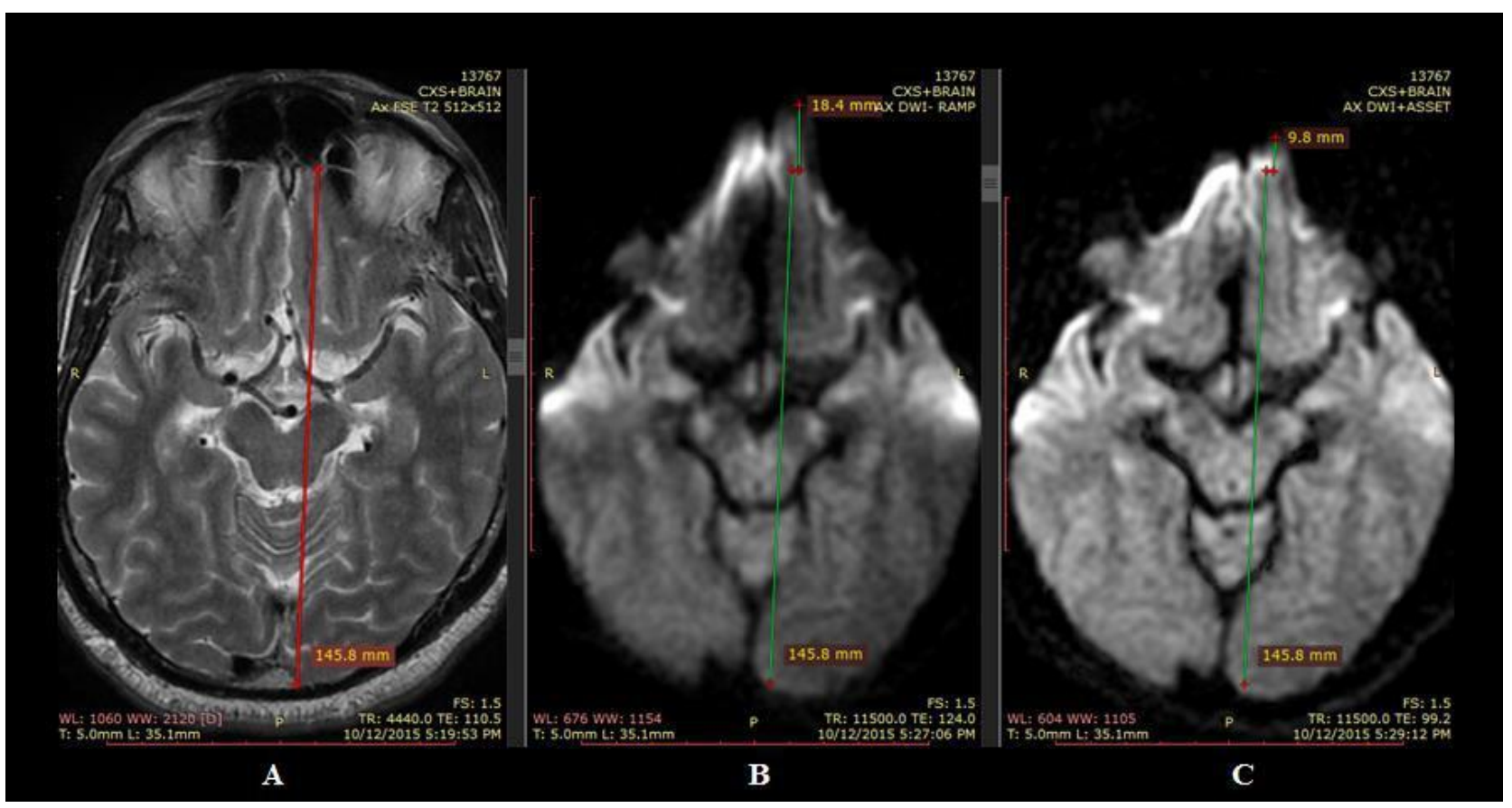

Figure (12): patient 9 ASSET with EPI-DWI. 


\subsubsection{Case $[10]$}

Figure (13) shows a slice of the last case in this group which shows the frontal sinus and susceptibility artifact, using ASSET decrease susceptibility artifact and increase resolution (C).

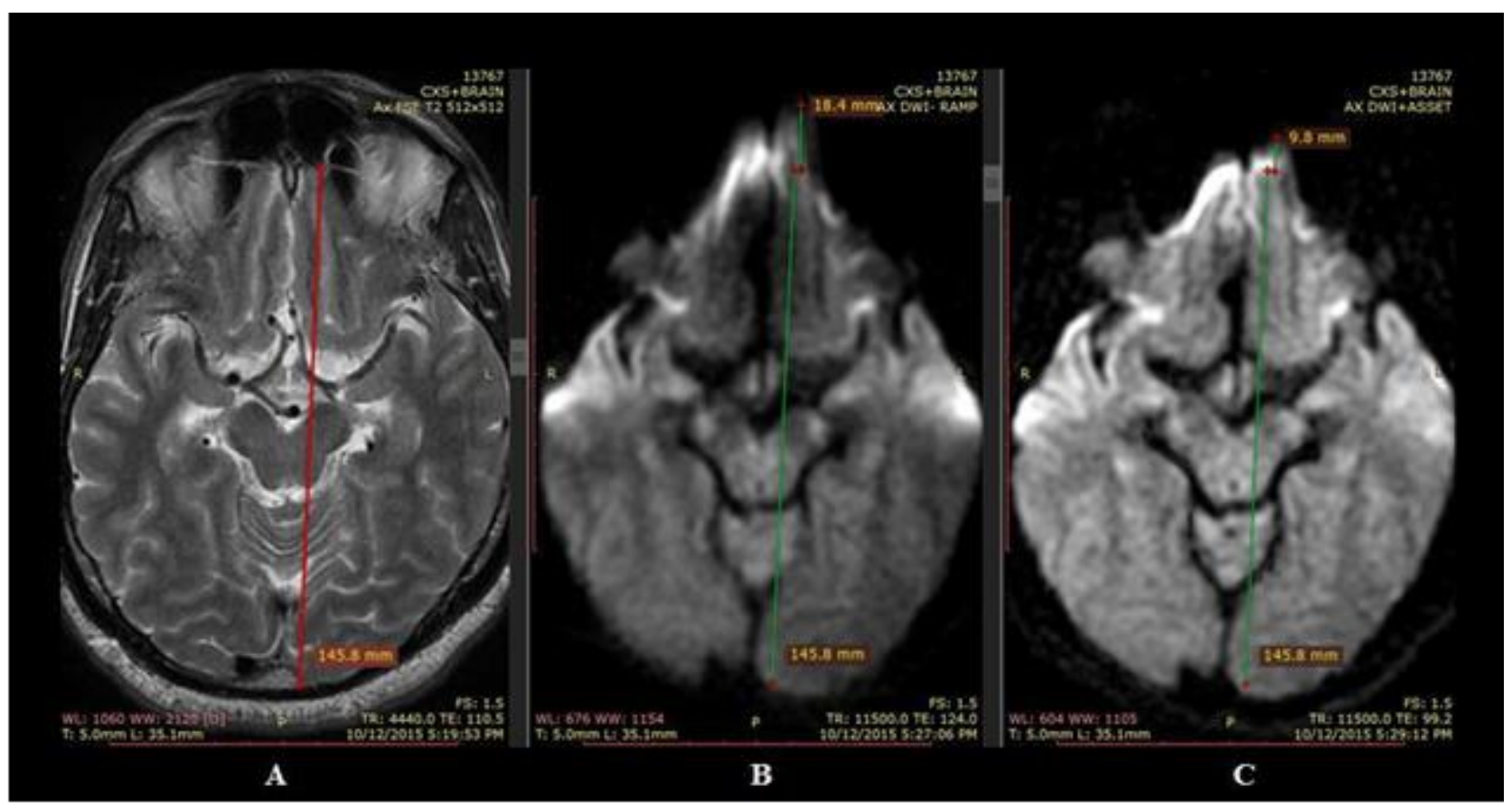

Figure (13): patient 10 frontal sinus and susceptibility artifacts

Table (3) shows reduction percentage for voxel displacement in anterior region in DWI before and after using parallel imaging technique for the examined five cases. Table (4) shows the reduction percentage in posterior region for the first three cases, for the last two cases there is no posterior artifact was detected.

Table [3] voxel displacement $(\mathrm{mm})$ in anterior region after using ASSET compared with those one without ASSET.

\begin{tabular}{|c|c|c|c|}
\hline Cases & $\begin{array}{c}\text { voxel displacement }(\mathbf{m m}) \text { in } \\
\text { DWI without ASSET } \\
\text { WI without ASSDET }\end{array}$ & $\begin{array}{c}\text { voxel displacement }(\mathbf{m m}) \text { in } \\
\text { DWI without ramp sampling } \\
\text { DWI after ASSET }\end{array}$ & Reduction percentage \\
\hline 6 & 7.6 & 3.7 & $51.30 \%$ \\
\hline 7 & 12.1 & 5.7 & $52.90 \%$ \\
\hline 8 & 15.7 & 7.7 & $50.90 \%$ \\
\hline 9 & 19.9 & 5.9 & $70.00 \%$ \\
\hline 10 & 18.4 & 9.8 & $46.70 \%$ \\
\hline & & & \\
\hline
\end{tabular}


Table [4] voxel displacement $(\mathrm{mm})$ in posterior region after using ASSET compared with those one without ASSET.

\begin{tabular}{|c|c|c|c|}
\hline Cases & $\begin{array}{l}\text { voxel displacement }(\mathbf{m m}) \text { in } \\
\text { DWI without ASSET }\end{array}$ & $\begin{array}{l}\text { voxel displacement }(\mathbf{m m}) \text { in } \\
\text { DWI after ASSET }\end{array}$ & Reduction percentage \\
\hline 6 & 13.7 & 9 & $34.30 \%$ \\
\hline 8 & 7.1 & 4.6 & $35.20 \%$ \\
\hline 3.4 & - & $100.0 \%$ \\
\hline
\end{tabular}

According to table [3] echo-planner DWI acquired with PI technique have GDA reduced to about $54.36 \%$ in frontal lobe more than this artifact in EPI-DWI acquire without parallel imaging and about $34.8 \%$ in occipital region according to table [4]. It noticed that Using parallel imaging decrease (TE) and reduces (SNR). ASSET showed increased resolution, decrease noise. From tables [3] and [4] and figures (9 to 13) it is obvious that acquiring EPI-DWI with parallel imaging technique decrease geometric distortion artifact and noise in addition to high resolution, In particular that it doesn't increase the scan time.

\subsection{Effect of Ramp sampling and ASSET}

in this step we have used both strategies (ramp sampling and ASSET) instead of using only one strategy and compared the acquired images with the same one acquired with only one strategy in these cases is ramp sampling, the following five cases [11, 12, 13, 14 and 15] show the result of applying both strategies on the same DWI sequence:

\subsubsection{Case [11]}

Figure (14) shows first a slice of the first case in this group, image (B) shows DWI acquire with ramp sampling technique it seem to be blurring and have low resolution when compared with image $(C)$ which acquired with both ramp sampling and ASSET techniques.

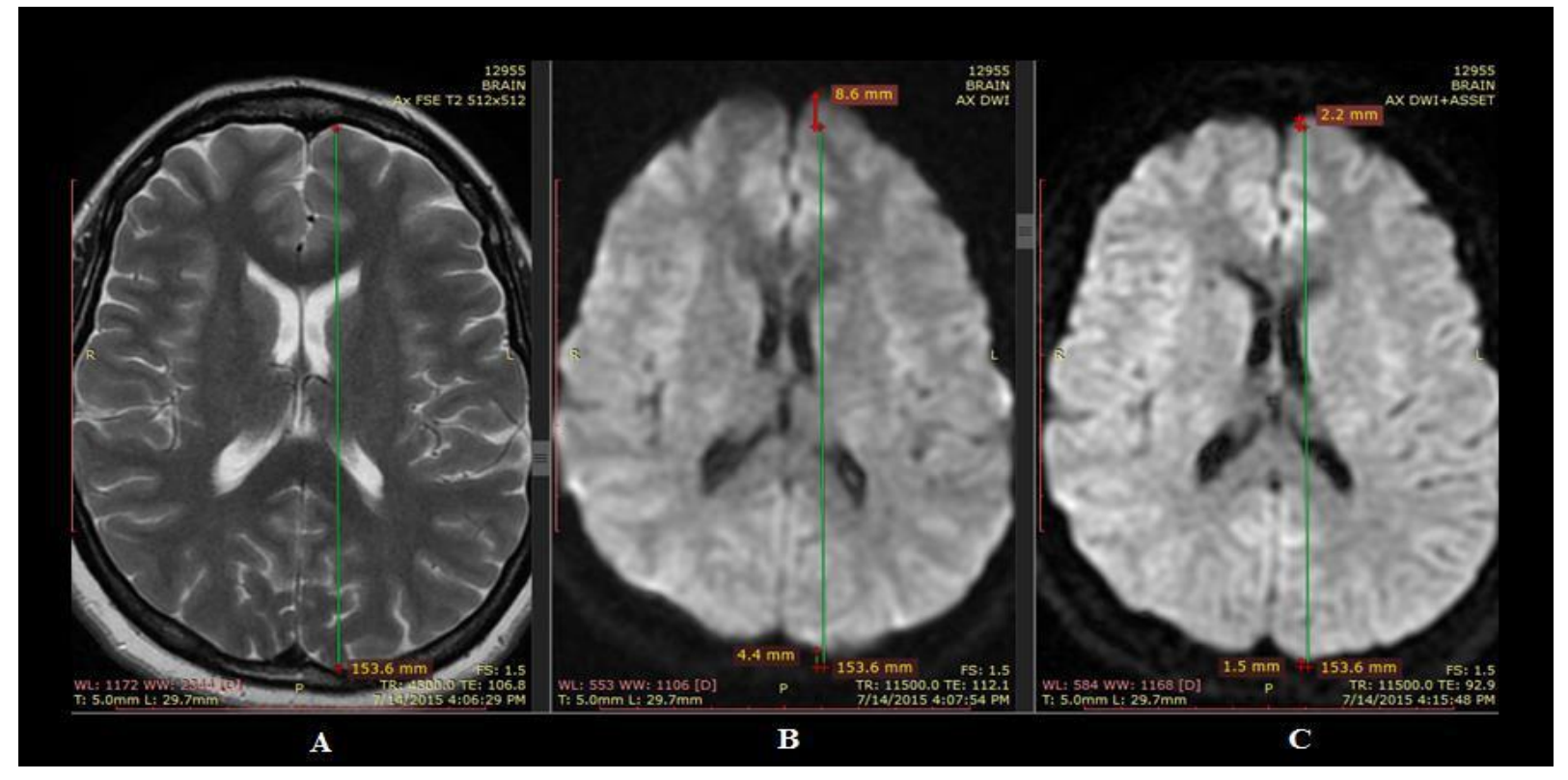

Figure (14): Patient 11 DWI acquire with ramp sampling 


\subsubsection{Case [12]}

Figure (15) shows the second case in this group, although we showed that using ramp sampling decrease geometric distortion artifact in EPI-DWI ( table [1], [2] ), using both techniques together (ramp sampling+ ASSET) (15- C) shows more reduction in this artifact in addition to increase in resolution. Figure (16) shows another slice in the upper brain for the same patient for measurements the artifact in anterior and posterior lobes.

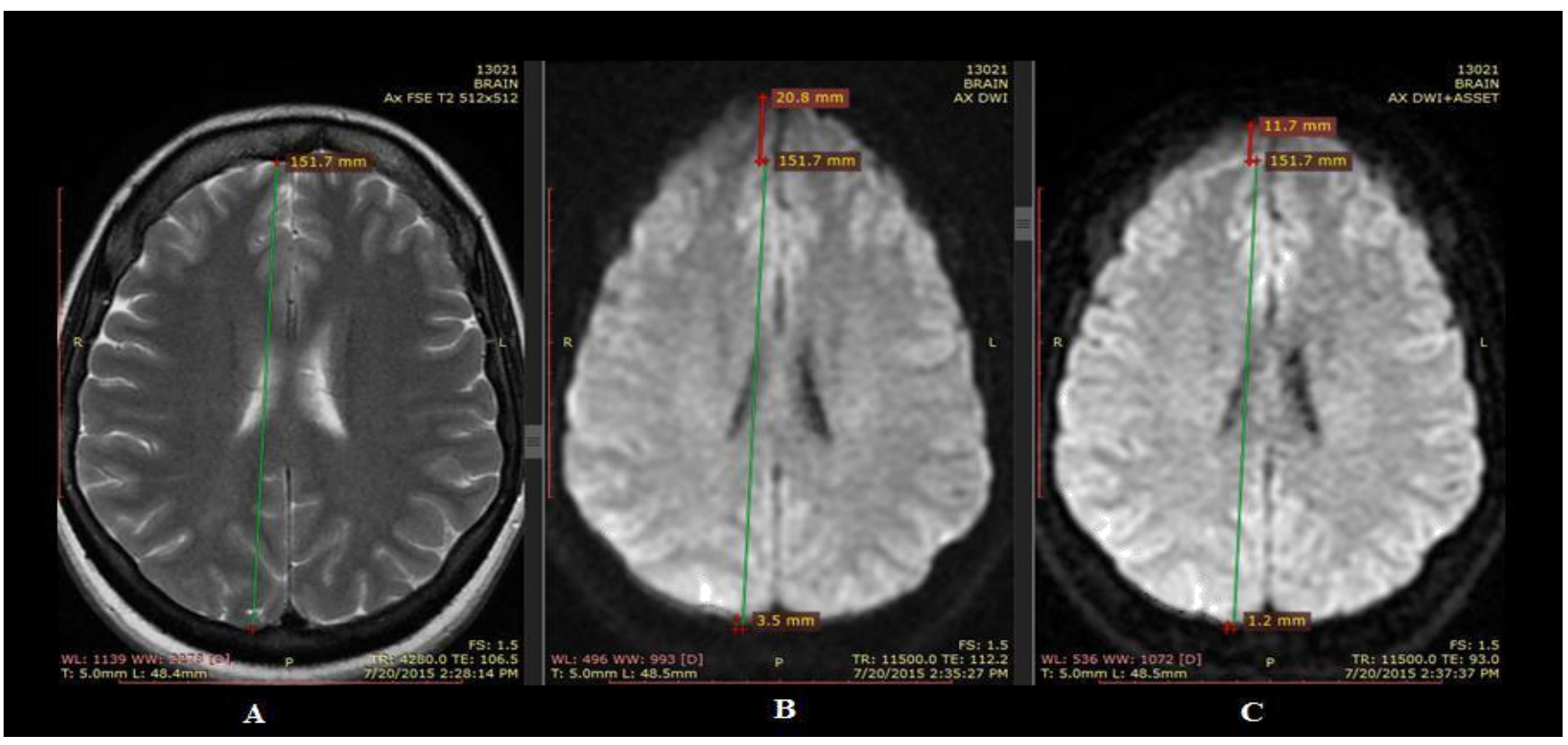

Figure (15): patient 12 first slice ramp sampling

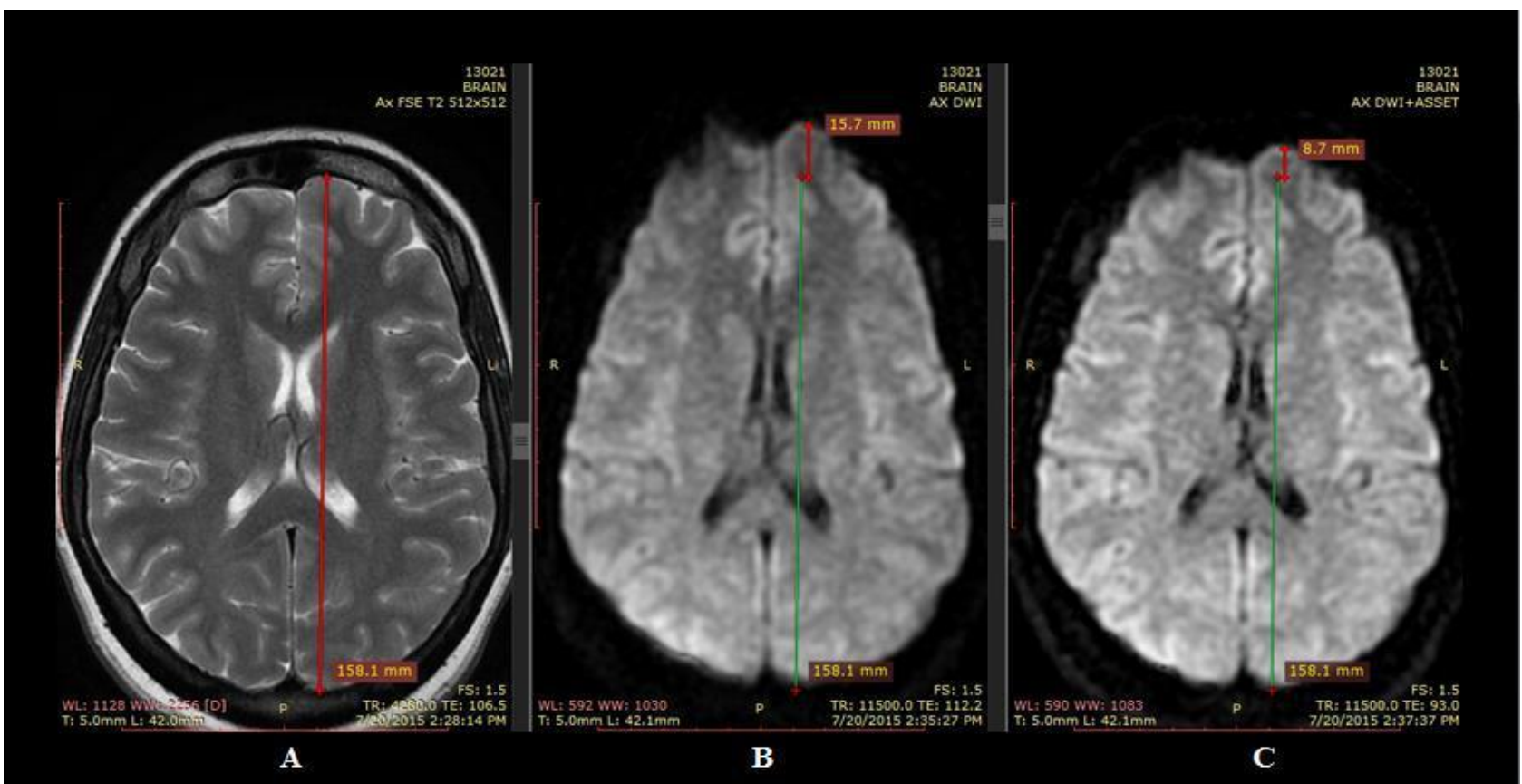

Figure (16): Patient 12 slice 2 


\subsubsection{Case [13]}

Figure (17) shows geometric distortion in anterior and posterior region of the third case and the reduction after using both techniques (C) compared with only using ramp sampling (B).

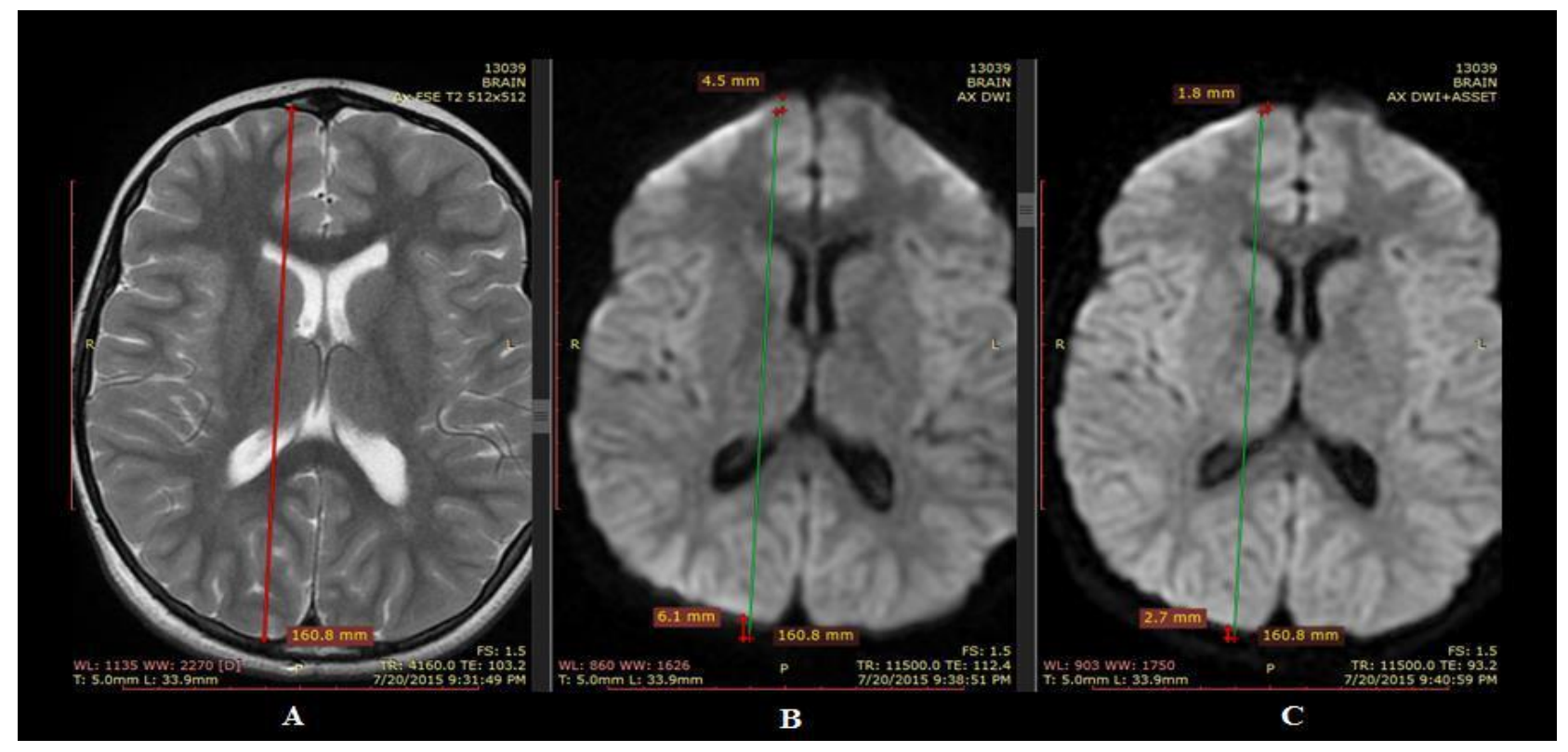

Figure (17): Patient 13 anterior and posterior region.

\subsubsection{Case [14]}

Figure (18) shows geometric distortion artifact in anterior and posterior lobe for normal brain of the forth case, DWI acquired with ramp sampling (B) shows blurring, more geometric distortion in both lobs and more noise when compared with that one acquired with both ramp sampling and ASSET (C).

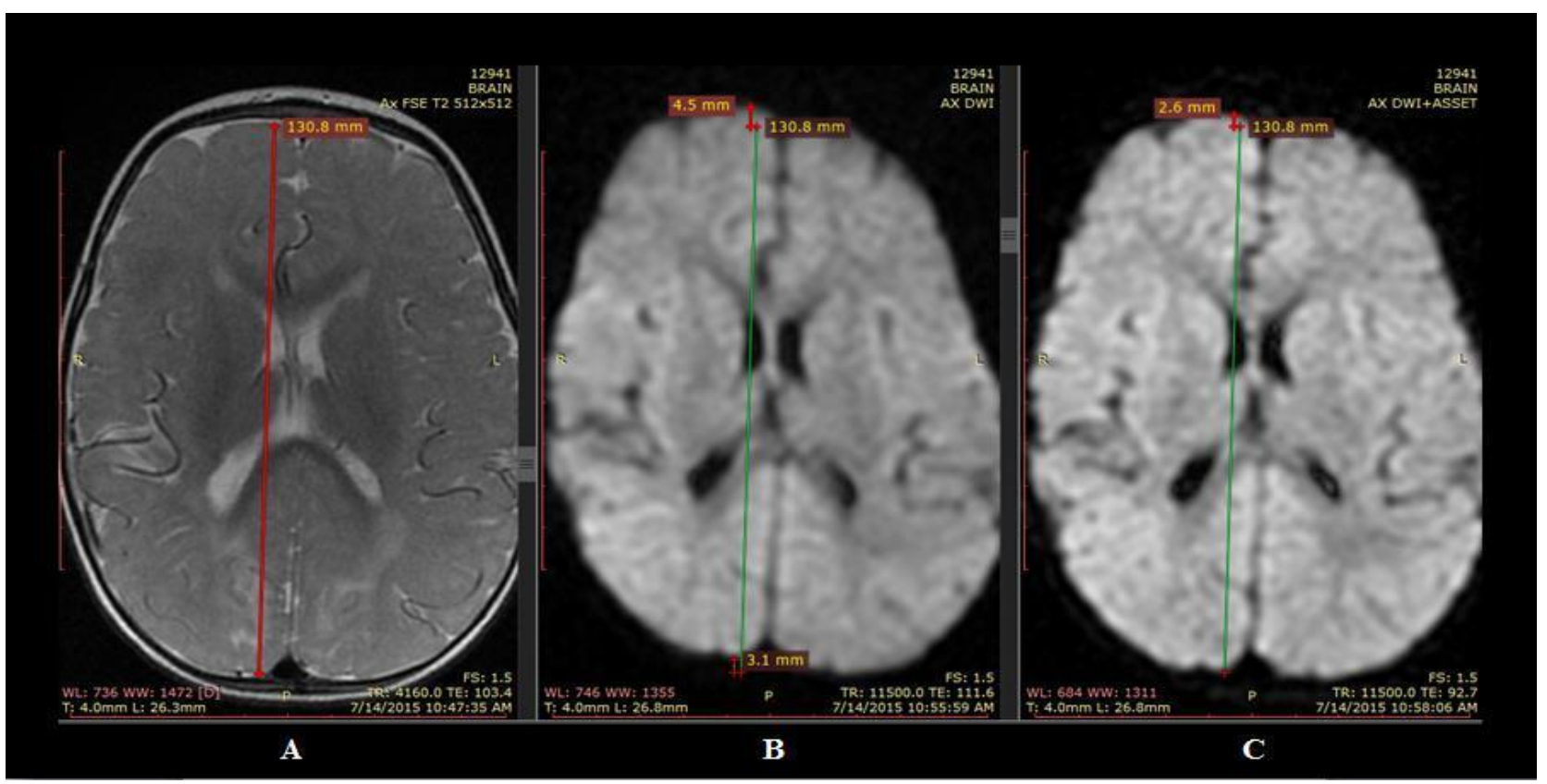

Figure (18): patient 14 anterior and posterior lobe for normal brain 


\subsection{Case [15]}

Figure (19): patient 15 pediatric case. Table (5) shows geometric distortion artifact in DWI with ramp sampling and after using ramp sampling and ASSET and the reduction percentage in anterior region, table (6) shows the reduction percentage in posterior region

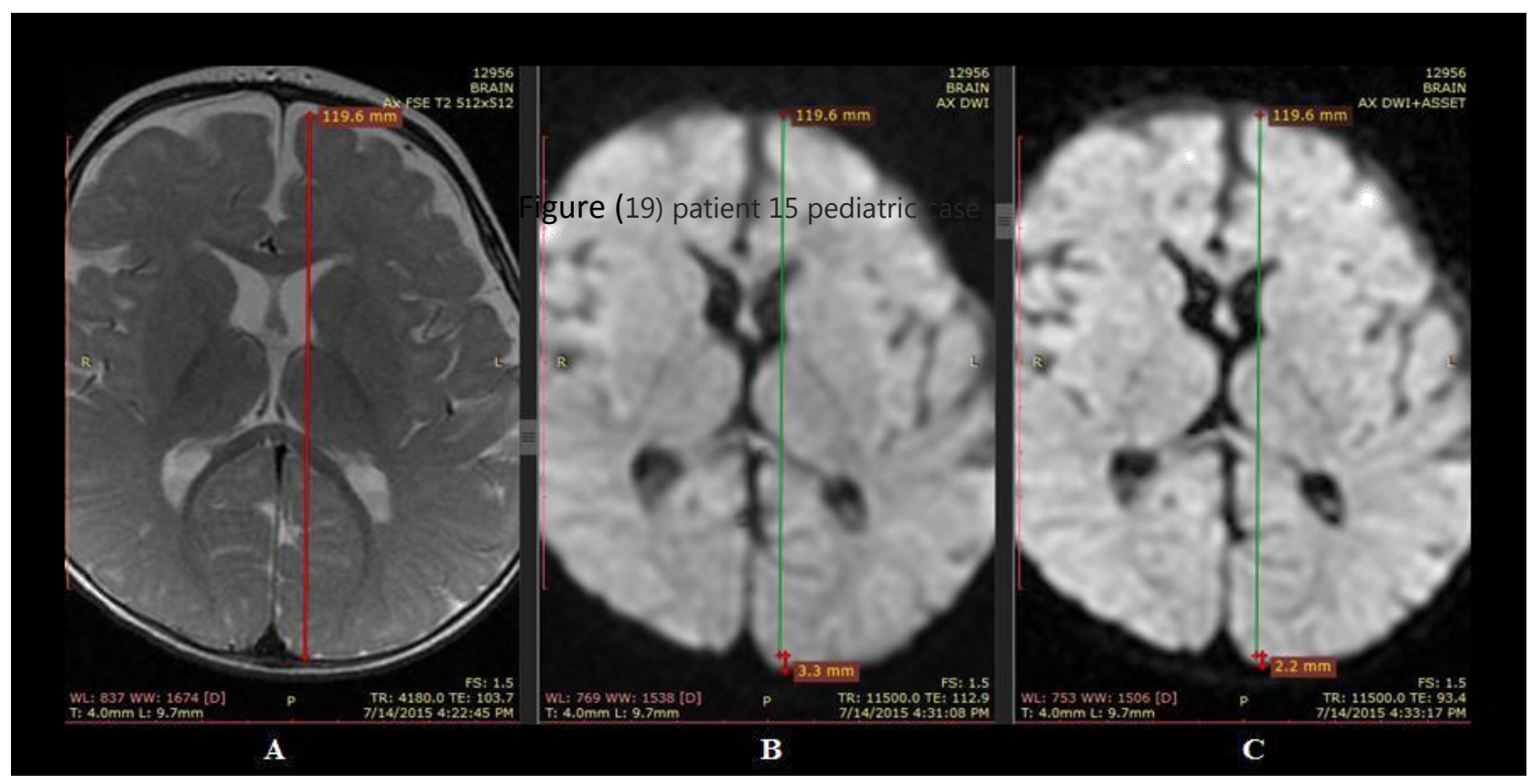

Table [5] voxel displacement $(\mathrm{mm})$ in anterior region after using both ramp sampling and ASSET compared with those one with ramp sampling only.

\begin{tabular}{|c|c|c|c|c|}
\hline Cases & $\begin{array}{l}\text { voxel displacement }(\mathrm{mm}) \text { in } \\
\text { DWI with ramp sampling }\end{array}$ & $\begin{array}{l}\text { voxel displacement } \\
\text { DWI with ramp } \\
\text { and ASSET }\end{array}$ & $\begin{array}{l}(\mathrm{mm}) \text { in } \\
\text { sampling }\end{array}$ & Reduction percentage \\
\hline 11 & 4.4 & 1.5 & & $65.90 \%$ \\
\hline 12 & 6.5 & 3.8 & & $35.70 \%$ \\
\hline 13 & 6.1 & 2.7 & & $55.70 \%$ \\
\hline 14 & 3.1 & - & & $100.0 \%$ \\
\hline 15 & 3.3 & 2.2 & & $33.00 \%$ \\
\hline
\end{tabular}

According to table [5]; acquiring EPI-DW images with two strategies Ramp sampling and parallel imaging reduce geometric distortion artifact in frontal lobe with approximately $53 \%$, and about $55 \%$ reduction in occipital lobe according to table [6] when compared acquired images with that one acquired with ramp sampling only. Using both strategies provide more increase in resolution, contrast and reduction in noise. Scan time still as it is after using both techniques. 
Table [6] voxel displacement $(\mathrm{mm})$ in posterior region after using both ramp sampling and ASSET compared with those one with ramp sampling only.

\begin{tabular}{|l|c|c|c|}
\hline Cases & voxel displacement $\mathbf{( m m})$ in & voxel displacement $(\mathbf{m m})$ in & Reduction percentage \\
& DWI with ramp sampling & DWI with ramp sampling & \\
\hline $\mathbf{1 1}$ & 8.6 & 2.2 & \\
\hline $\mathbf{1 2}$ (slice 1) & 15.7 & 8.7 & $74.40 \%$ \\
\hline $\mathbf{1 2}$ (slice 2) & 88.0 & 33.7 & $44.50 \%$ \\
\hline $\mathbf{1 3}$ & 4.5 & 1.8 & $96.00 \%$ \\
\hline $\mathbf{1 4}$ & 4.5 & 2.6 & $60.00 \%$ \\
\hline & & & $42.20 \%$ \\
\hline
\end{tabular}

\section{Conclusion}

Many parameters can affect on quality of MRI image . We showed that Ramp sampling and ASSET can be used to decrease geometric distortion artifact in EPI-DWI for brain in addition to increasing image resolution and decreasing noise Although ramp sampling shows reduction in geometric distortion artifact and signal loss, parallel imaging technique impact more positively in images artifacts and resolution. Maximum reduction for geometric distortion artifact and susceptibility artifact in air-tissue interface can be achieved by using both strategies together during data acquisition.

\section{References}

1. Le Bihan, D., Poupon, C., Amadon, A., \& Lethimonnier, F. (2006). Artifacts and pitfalls in diffusion MRI. Journal of Magnetic Resonance Imaging: An Official Journal of the International Society for Magnetic Resonance in Medicine, 24(3), 478-488.D. K. Jones, Diffusion MRI: Theory, Methods, and Applications. Oxford University Press, Inc., 2011.

2. C Bhushan, J.P Haldar, A.A Joshi, R.M Leahy, "Correcting Susceptibility-Induced Distortion in Diffusion-Weighted MRI using Constrained Nonrigid Registration," Signal and Information Processing Association Annual Summit and Conference (APSIPA), Asia-Pacific, 2012.

3. K. Kantarci, R. Avula, M. Senjem, A. Samikoglu, B. Zhang,S. Weigand, S. Przybelski, H. Edmonson, P. Vemuri, D. Knopman, T. Ferman, B. Boeve, R. Petersen, and C. Jack, "Dementia with Lewy bodies and Alzheimer disease: Neurodegenerative patterns characterized by DTI," Neurology, vol. 74, no. 22, pp. 1814-1821, 2010.

5. J. L. R. Andersson and S. Skare, "Image distortion and its correction in diffusion MRI," in Diffusion MRI: Theory, Methods, and Applications (D. K. Jones, ed.), 2010.

6. P. Jezzard and R. S. Balaban, "Correction for geometric distortion in echo planar images from B0 field variations," Magnetic Resonance in Medicine, vol. 34, no. 1, pp. 65-73, 1995.

7. D. K. Jones and M. Cercignani, "Twenty five pitfalls in the analysis of diffusion MRI data," NMR in Biomedicine, vol. 23, no. 7, pp. 803-820, 2010. 
8. C. Studholme, R. T. Constable, and J. S. Duncan, "Accurate alignment of functional EPI data to anatomical MRI using a physics-based distortion model," IEEE Transactions on Medical Imaging, vol. 19, pp. 1115 -1127, nov. 2000.

9. M. O. Irfanoglu, L. Walker, J. Sarlls, S. Marenco, and C. Pierpaoli, "Efects of image distortions originating from susceptibility variations and concomitant fields on diffusion MRI tractography results," NeuroImage, vol. 61, no. 1, pp. 275 -288, 2012.

10. K. V. Embleton, H. A. Haroon, D. M. Morris, M. A. L. Ralph, and G. J. Parker, "Distortion correction for diffusion-weighted MRI tractography and fMRI in the temporal lobes," Human Brain Mapping, vol. 31, no. 10, pp. 1570-1587, 2010.

11. Oghabian, M. A., Faeghi, F., \& Tohidnia, M. R. (2012). Effect of phase-encoding reduction on geometric distortion and BOLD signal changes in fMRI. Iranian Journal of Medical Physics, 9(4), 275-281.

12. Andrä, W., \& Nowak, H. (Eds.). (2007). Magnetism in medicine: a handbook. John Wiley \& Sons.

13. J. sanchez- Gonzalez: How to identify and avoid artifacts in DWI. A. Luna et al., Diffusion MRI Outside the Brain, DOI 10.1007/978-3-642-21052-5_2, Springer-Verlag Berlin Heidelberg 2012

14. Gamal Fathalla M. Mahdaly, "Geometric distortion artifact remedy in DWI: A novel comprehensive approach," OMICS J Radiology, August 14-16, Holiday Inn Chicago-North Shore, IL, USA, 2013.

15. A Gholipour, N Kehtarnavaz, B Scherrer, S.K Warfield, "On the Accuracy of Unwarping Techniques for the Correction of Susceptibility-Induced Geometric Distortion in Magnetic Resonance Echo-Planar Images," IEEE engineering in medicine and biology society. Annual conference, 6997-700, 2011. 